\section{Transparency of Sea-Water}

THE transparency of sea-water has hitherto been studied, either by means of the Secchi disc or, more recently, by measuring the intensity of submarine daylight at different depths by means of photo. electric cells, Both methods are limited to com. paratively small depths, where the residual daylight has a measurable intensity. In addition, the results, if no colour filters are used, are affected by the changes in spectral composition which daylight undergoes with increasing depth.

For some time, an instrument specially constructed for measuring in situ the transparency of sea-water to electric light has been used from this station as well as from our research ship the Skagerak ${ }^{1}$. A horizontal beam of electric torch-light passing from a closed metal casing into the water through a plateglass window, and reflected by a mirror at a distance of one metre, passes through a second window on to a rectifying selenium cell. A 4-lead rubber-insulated electric cable serves to carry the lamp-current from a battery of storage cells and also for connecting the rectifying cell with a micro-ammeter, on which the photo-current is read. Keeping the lamp current perfectly constant, the intensity of the photo-current gives a measure of the transparency of the 2 metres of sea-water through which the light passes, and thus affords means for calculating the extinction coefficient of the water for the light used. The transparency meter, which is quite simple to use, has revealed surprisingly abrupt changes in the trans. parency of the sea-water in our fjords at certain depths, where the photo-current may vary by fifty per cent or more within a layer less than 1 metre thick.

A similar instrument without mirror serves to measure the light scattered backwards from a strong beam of light projected into the water. The curves giving the intensity : depth relation obtained, on one hand with the scattering meter, and on the other hand with the transparency meter, are found to be antisymmetrical to one another, a sharp maximum in one curve corresponding to an equally distinct minimum in the other curve. This indicates that the large variations with the depth found in the trans. parency are mainly due to the presence of suspended particles in varying amounts. A microscopic examination of the particles has shown them to be largely organic, either detritus or, at certain seasons, phytoplankton. Either of the two instruments here described, therefore, affords a simple means for discovering and locating the 'clouds' of organic particlos occurring at certain depths, which are of outstanding importance to biologists ${ }^{2}$.

Recently, with a transparency meter constructed for work in greater depths, the transparency of the water in the central Skagerak has been investigated down to a depth of 500 metres. In 250 metres depth, a maximum transparency was found, whereas the influence from the bottom sediment, affecting the transparency of the lowest strata, was observable already at 50 metres above the bottom. On the other hand, in isolated depths within the fjords, the water less than 1 metre above the sea-bottom was found to have a high transparency, proving the water to have been at rest for a considerable time. Thus conclusions regarding the movements of the bottom-layers may be drawn from measurements of the transparency.

Bornö Station. Hans PetTersson.

Nov. 30.

1 Meddel. Oceanogr. Inst., Göteborgs Högskola, Nos, 7 and 9 (1934).

'J. Conseil Perm. pour l'Expl. de la Mer, 10, (1), 48 (1935).

\section{Experimental Investigation on the Magnetic Double Refraction of Ionised Air}

THE theory of the propagation of electromagnetic waves in the ionised upper atmosphere of the earth, as influenced by the earth's magnetic field, has been developed by Appleton ${ }^{1}$, Hartroe ${ }^{2}$, Cioldstein ${ }^{3}$ and others. Investigations on the magnetic splitting and polarisation of radio waves returned from ionospheric layers have confirmed this so-called magneto-ionic theory. Laboratory experiments have also been carried out in this connexion. Benner ${ }^{4}$, for example, has shown that at the approach of the critical value of the magnetic field $(\mathrm{He} / m c=$ the angular frequency of the incident waves), the values of the refractive index and the conductivity of a space containing free electrons change abruptly. Similar observations have been made by $H$. Gutton ${ }^{5}$, and by Jonescue and Mihul $^{6}$. Appleton and Childs have shown ${ }^{7}$ that at this value the absorption of waves is greatly increased.

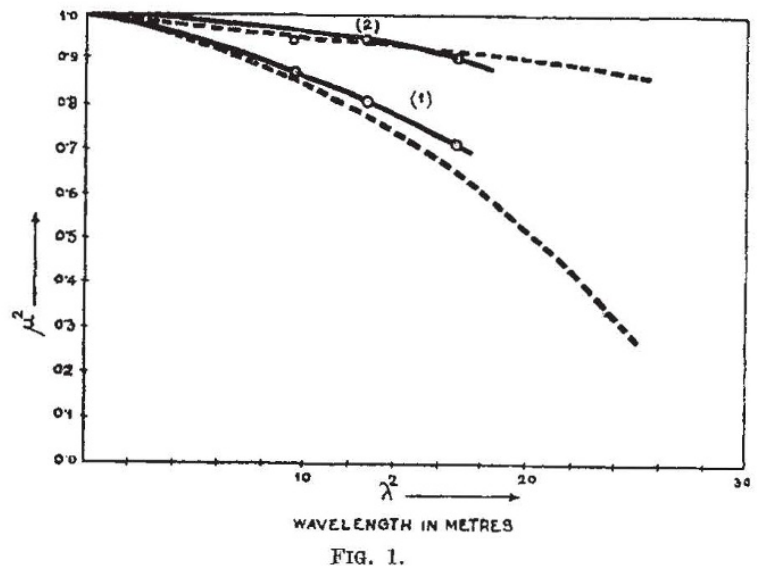

All these observations, from the point of view of the magneto-ionic theory, are for the so-called transverse type of propagation, and were made primarily with the object of demonstrating the phenomenon of magnetic resonance. The most striking result of the magneto-ionic theory-the phenomenon of double refraction-has not, however, received adequate attention from exporimental investigators, and, so far as we are aware, the only work in this connexion is that carried out by Keck ${ }^{8}$, who, working with a wave-length of $4 \mathrm{~cm}$. (sparkgenerated), has observed the Faraday effect in ionised gas in the presence of a magnetic field and explains the rotation of the plane of polarisation as due to double refraction.

We have recently carried out experiments in which, with a very simple disposition of apparatus, the actual splitting of the wave traversing a column of ionised gas under the influence of a steady magnetic field is observed, and the dispersion and the differential absorption of the split waves studied quantitatively.

The experimental arrangement was the same as that described in a recent note by Mitra and Banerjee on their study of the dielectric constant of ionised air ${ }^{\theta}$. The discharge tube containing the ionised air is placed between a pair of Lechor wires with its length parallel to them. The Lecher wires are energised by a high-frequency valve oseillator $(\lambda=3-4 \mathrm{~m}$.), and the lengths of the waves propagated along the lines, through the ionised air in the discharge tube, are measured in the usual way by noting the positions of resonance on the wires. A cylindrical 